\title{
Nutritional interventions: the evidence
}

\author{
Martijn B. Katan \\ Wageningen Centre for Food Sciences and Division of Human Nutrition and Epidemiology, \\ Wageningen Agricultural University, Bomenweg 2, 6703 HD Wageningen, The Netherlands
}

Some of the foods and supplements that claim to prevent or cure cardiovascular disease have no scientific basis. However, a number of dietary interventions have been thoroughly researched, and several of these interventions do reduce the risk of cardiovascular disease. The present summary reviews such interventions.

Advice to change the nature of dietary fat rests on a solid research foundation: it is backed up by large-scale prospective epidemiology ( $\mathrm{Hu}$ et al. 1997), randomized clinical trials (Sacks \& Katan, 2000), and mechanistic insights (Spady \& Dietschy, 1985). Feeding trials show that replacement of saturated or partially-hydrogenated fats by vegetable oils such as unhydrogenated soyabean, olive or sunflower oil reduces plasma LDL-cholesterol and the total: HDL-cholesterol ratio (Mensink \& Katan, 1992). Such replacement should therefore reduce CHD incidence, and that is indeed seen in clinical trials of such oils. Data from clinical trials with morbidity and mortality end points are less extensive than those for drugs, because such trials are expensive. However, this factor is made up for by extensive observational epidemiological data. Evidence is strongest for oils rich in linoleic acid ( $n-6$ polyunsaturated fatty acids), but oils rich in oleic acid (monounsaturated fatty acids) are probably about as effective. There is also epidemiological and clinical trial evidence that small amounts of $n-3$ polyunsaturated fatty acids such as those found in fatty fish or fish oil reduce CHD mortality (Katan, 1995).n-3 Fatty acids do not lower LDL-cholesterol (Harris, 1997), so their effect on CHD mortality must therefore be due to other mechanisms, with prevention of arrhythmia as a prime candidate. A related $n-3$ fatty acid is $\alpha$-linolenic acid, which is found in rapeseed and soyabean oil. Intake of $\alpha$-linolenic acid is also associated with lower rates of CHD, but clinical trial evidence is weaker than that for the fatty acids from fish.

Thus, replacement of hard fats by unsaturated oils reduces the risk of CHD. In contrast, the effectiveness of a reduction in fat intake and an increase in carbohydrate intake has been less well established (Katan et al. 1997). Such low-fat high-carbohydrate diets decrease both LDL- and HDL-cholesterol and increase fasting plasma triacylglycerols, and the predicted net effect of these blood lipid changes on CHD risk is nil. Also, clinical trial evidence is absent, and prospective epidemiological data show no advantages of diets high in carbohydrates. Dietary fibre is an exception; high intakes of cereal fibre are associated fairly consistently with a reduced risk of CHD in observational studies (Slavin et al. 1999). This association does not prove causality, but in combination with the laxative effects of whole grains it does support advice to eat whole-grain foods.

Next to blood lipids, hypertension is a major risk factor for cardiovascular disease. Although the effect of $\mathrm{Na}$ on blood pressure has been overestimated in the past, $\mathrm{Na}$ reduction does reduce blood pressure by $3-4 \mathrm{mmHg}$ in hypertensive patients, and the effect is potentiated by an increased intake of $\mathrm{K}$. Alcohol raises blood pressure, as does obesity. There is preliminary but important evidence that low-fat dairy products, fruits and vegetables contain substances that lower blood pressure (Appel et al. 1997); further tests of these findings are eagerly awaited.

Evidence for effects of antioxidants and other 'bioactive' compounds on cardiovascular disease risk is no more than tentative. There is as yet no solid evidence in man that increased intake of antioxidants promotes health, but highdose vitamin E was modestly effective in preventing CHD in the GISSI prevenzione trial. Other trials of vitamin $\mathrm{E}$ are underway. Phyto-oestrogens are polyphenols present in soyabeans and flaxseeds. They have hormonal and nonhormonal activities in vitro and in animals, and are under investigation for their effects on many diseases, but evidence of safety and efficacy in man is scarce.

Elevated plasma concentrations of homocysteine are associated with increased risk of cardiovascular disease. Homocysteine can be lowered very effectively by modest increases in the intake of folic acid, but whether this intervention reduces risk is not yet clear (Verhoef et al. 1998). The safety and efficacy of interventions to lower homocysteine will be resolved in a few years as clinical trials emerge from the pipeline. 
In summary, diet has been successful in reducing cardiovascular disease risk in the population, and dietary changes have probably contributed to the fall in cardiovascular disease mortality seen in most affluent countries over the past 30 years. Plant foods may contain additional components that lower cardiovascular disease risk, with folate and vitamin $\mathrm{E}$ as the most promising candidates; whether these components live up to their promises will become clear in the next few years as the outcomes of clinical trials are reported.

\section{Cardiovascular disease: Nutritional interventions: Dietary fats: Antioxidants: Plant foods}

\section{References}

Appel LJ, Moore TJ, Obarzanek E, Vollmer WM, Svetkey LP, Sacks FM, Bray GA, Vogt TM, Cutler JA, Windhauser MM, Lin PH \& Karanja N (1997) A Clinical trial of the effects of dietary patterns on blood pressure. New England Journal of Medicine 336, 1117-1124.

Harris WS (1997) n-3 Fatty acids and serum lipoproteins: human studies. American Journal of Clinical Nutrition 65, $1645 \mathrm{~S}-1654 \mathrm{~S}$

Hu F, Stampfer MJ, Manson JE, Rimm EB, Colditz GA \& Rosner BA (1997) Dietary fat intake and the risk of coronary heart disease in women. New England Journal of Medicine 337, 1491-1499.

Katan MB (1995) Fish and heart disease. New England Journal of Medicine 322, 1024-1025.

Katan MB, Willett WC \& Grundy SM (1997) Beyond low fat diets. New England Journal of Medicine 337, 563-566.
Mensink RP \& Katan MB (1992) Effect of dietary fatty acids on serum lipids and lipoproteins - a meta-analysis of 27 trials. Arteriosclerosis and Thrombosis 12, 911-919.

Sacks FM \& Katan MB (2000) The effects of dietary fats and carbohydrate on plasma lipoproteins and coronary heart disease: randomized clinical trials. American Journal of Medicine (In the Press).

Slavin J, Martini MC, Jacobs DR \& Marquart L (1999) Plausible mechanisms for the protectiveness of whole grains. American Journal of Clinical Nutrition 70, 459S-463S.

Spady DK \& Dietschy JM (1985) Dietary saturated triacylglycerols suppress hepatic low density lipoprotein receptor activity in the hamster. Proceedings of the National Academy of Sciences, USA 82, 4526-4530.

Verhoef P, Stampfer MJ \& Rimm EB (1998) Folate and coronary heart disease. Current Opinion in Lipidology 9, 17-22. 